\title{
Transactive Energy Based Aggregation of Prosumers as a Retailer
}

\author{
Xiao, Yunpeng; Wang, Xifan; Pinson, Pierre; Wang, Xiuli
}

Published in:

IEEE Transactions on Smart Grid

Link to article, DOI:

$10.1109 /$ tsg.2020.2976130

Publication date:

2020

Document Version

Peer reviewed version

Link back to DTU Orbit

Citation (APA):

Xiao, Y., Wang, X., Pinson, P., \& Wang, X. (2020). Transactive Energy Based Aggregation of Prosumers as a Retailer. IEEE Transactions on Smart Grid, PP(99). https://doi.org/10.1109/tsg.2020.2976130

\section{General rights}

Copyright and moral rights for the publications made accessible in the public portal are retained by the authors and/or other copyright owners and it is a condition of accessing publications that users recognise and abide by the legal requirements associated with these rights.

- Users may download and print one copy of any publication from the public portal for the purpose of private study or research.

- You may not further distribute the material or use it for any profit-making activity or commercial gain

- You may freely distribute the URL identifying the publication in the public portal

If you believe that this document breaches copyright please contact us providing details, and we will remove access to the work immediately and investigate your claim. 


\title{
Transactive Energy Based Aggregation of Prosumers as a Retailer
}

\author{
Yunpeng Xiao, Xifan Wang, Fellow, IEEE, Pierre Pinson, Fellow, IEEE, and Xiuli Wang, Senior Member, IEEE
}

\begin{abstract}
The rapid growth of distributed energy resources results in the proliferation of prosumers at the distribution level, who can both produce and consume energy. In order to harvest benefits of aggregation to obtain revenues in wholesale market and encourage direct interactions among prosumers and other flexible players at the same time, this paper proposes an aggregation framework for prosumers based on transactive energy, in which prosumers aggregate and trade in an independent, proactive and privacy-preserved manner without relying on a real central entity, while other flexible players could be benefited equally. The aggregation of prosumers as a whole behaves as a retailer that trades in wholesale market and towards end-users in retail market. Therefore, the problem is generalized as a bi-level multi-leader multi-follower game in which prosumers are leaders and end-users are followers. To realize the transactive energy based trading framework, an inner-outer iteration approach is proposed, where the outer iteration involves interactions among prosumers and end-users, and achieves final results including the retail price and optimal behaviors of all players. The inner iteration is conducted during each time of the outer iteration to solve end-users' optimal consuming profiles. The whole iteration process involves the independent decision makings of players, and only relies on exchange of information of retail price and prosumers' offers instead of players' private information. Case studies are then carried out demonstrating the proposed transactive energy based aggregation framework for prosumers could decrease the retail price, increase revenues for both prosumers and end-users, and reduce the peak load.
\end{abstract}

Index Terms-Electricity market, inner-outer iteration approach, prosumer, retailer, transactive energy.

\section{NOMENCLATURE}

\section{Indices}

$\begin{array}{ll}i & \text { Index of prosumers. } \\ j & \text { Index of end-users. } \\ k & \text { Index of blocks of prosumer's offers. } \\ t, l & \text { Index of time. } \\ m_{i}, m_{j} & \text { Index of non-interruptible and deferrable tasks of } \\ & \text { prosumer/end-user. }\end{array}$

This work was supported by the research project "Research and application of energy price mechanism design theory and key technologies to facilitate renewable energy integration" of State Grid Corporation of China under Grant SGSC0000KXJS1800340.

Y. Xiao is with the School of Electrical Engineering, Xi'an Jiaotong University, Xi'an 710049, China, and also with the Power Dispatching and Control Center, Guangdong Power Grid Corporation, Guangzhou 510600, China (email: xiaoyunpengee@163.com).

$\mathrm{X}$. Wang and X. Wang are with the State Key Laboratory on Electrical Insulation and Power Equipment and the School of Electrical Engineering, Xi' an Jiaotong University, Xi'an 710049, China (e-mail: xfwang@ @ail.xjtu.edu.cn; xiuliw@mail.xjtu.edu.cn).

P. Pinson is with the Department of Electrical Engineering, Technical University of Denmark, Kgs. Lyngby, Denmark (email: ppin@elektro.dtu.dk).

\author{
$n_{i}, n_{j}$ Index of interruptible and deferrable tasks of \\ prosumer/end-user. \\ $r, u \quad$ Index of numbers of iteration.
}

\section{Parameters}

$\begin{array}{ll}\lambda^{D A} & \text { Day-ahead market price. } \\ \eta^{E V} & \text { Efficiency of energy over distance of EV. } \\ \eta^{E V c}, \eta^{E V d} & \text { Charging/discharging efficiency of EV. } \\ D^{E V} & \text { Driving distance of EV. } \\ E^{i d} & \text { Total consumed energy of interruptible and } \\ & \text { deferrable task. } \\ E^{E V, i n i} & \text { Initial energy in battery of EV. } \\ E^{E V, \max } & \text { Maximum energy in battery of EV. } \\ E^{E V, \min } & \text { Minimum energy in battery of EV. } \\ P^{E V c, \max } & \text { Maximum charging power of EV. } \\ P^{E V d, \max } & \text { Maximum discharging power of EV. } \\ P^{P G} & \text { Generated power of prosumer. } \\ P^{i d, \max } & \text { Maximum power of interruptible and de- } \\ t^{i d 1}, t^{i d 2} & \text { ferrable task. } \\ t^{n i d 1}, t^{n i d 2} & \text { Starting/ending time of interruptible and de- } \\ & \text { Eerrable task. } \\ t^{E V 1}, t^{E V 2} & \text { Earliest/latest starting time } \\ \delta & \text { Departure/arrival time of EV. } \\ & \text { Constant revenue for selling per-unit of ener- } \\ & \text { gy in retail market. }\end{array}$

Variables

$u^{n i d}$
$u^{E V c}, u^{E V d}$
$E^{E V}$
$P^{n i n d}$
$P^{n i d}$
$P^{i d}$
$P^{E V c}, P^{E V d}$
$P^{E V u}$
$P^{E V}$
$P^{P C}$
$P^{P O}$
$P^{C}$

Binary indicating operation mode of noninterruptible and deferrable task.

Binaries indicating charging/discharging state of EV.

Energy in battery of EV.

Power of non-interruptible and nondeferrable task.

Power of non-interruptible and deferrable task.

Power of interruptible and deferrable task.

Charging/discharging power of EV.

Consumed power of EV.

Overall power of EV.

Power traded between a specified prosumer and a specified end-user.

Offered quantity of prosumer.

Total consumed power of end-user. 
$P^{D A}, P^{P} \quad$ Power sold in DA market and retail market of prosumer.

$U^{P}, U^{C} \quad$ Revenue of prosumer/end-user.

$\lambda^{P O} \quad$ Offered price of prosumer.

$\lambda^{R} \quad$ Retail price.

\section{INTRODUCTION}

W ITH the rapid growth of distributed energy resources (DERs), such as solar photovoltaic (PV) panels and electric vehicles (EVs), a large number of costumers now become prosumers that both consume and produce energy [1-2]. The prosumers' active participation in the electricity market is one of the key features of smart grid and attracts much concentration nowadays [3-4]. Transactive energy (TE) is emerging for coordinated operation of vast numbers of actively involved DERs in smart grid. In a TE environment, DER owners behave independently and participate proactively in energy trading based on the exchange of value-based information instead of disclosing their detailed power parameters and preferences to a third-party [5-6]. In order to efficiently accommodate prosumers and promote their profitabilities, plenty of works have offered solutions to designing the TE based trading frameworks for prosumers.

Some of the existing studies focus on trading frameworks within the local community, due to the small capacities of prosumers. A local energy market is established in [7], where the price is generated iteratively by the interactions of prosumers and other flexible players. Local energy markets can be further linked to the wholesale market by a two-stage stochastic model to achieve a fully TE based trading scheme [8]. On the other hand, the peer-to-peer market structure involving direct multi-bilateral negotiations among flexible players is also proposed, where products and prices can be differentiated [9]. To address this problem, decentralized algorithms are put forward, including the alternating direction method of multipliers [10] and consensus based approaches [11]. In the Netherlands, a platform to trade self-generated energy of customers has already been established and implemented, where the power transaction occurs in peers under certain contracts [12]. The above works focus on enabling direct interactions and proactive transactions for individual players in a retail-level community, nevertheless, the benefits of sharing flexibilities within the community could also empower the prosumers as an aggregation to obtain greater revenues in wholesale market.

In such studies investigating on behaviors of the aggregation of prosumers or other flexible players in wholesale market, a real central entity always exists to decide on the optimal strategies for the whole aggregation by direct controlling or exchanging value-based information with prosumers and other flexible players. A retailer [13] or the distribution system operator [14] usually serve as the real central entity for the aggregation. A bi-level model can be adopted that accounts for a Stackelberg relationship between the real central entity (leader) and the flexible players (followers) [13-15]. As direct control of prosumers' behaviors induces privacy issues [1617], approaches only involving the exchange of value-based information between the real central entity and flexible players are broadly discussed, especially in the context of TE. A TE based real-time (RT) EV charging management approach is put forward in which the EV owners only provide their RT charging requirements and preferences in response to the price signal of building energy management, instead of the privacy information, such as the detailed driving plans [18]. A day-ahead (DA) transactive platform to accommodate widely dispersed DERs is designed that allows DERs to transact with the wholesale market and prosumers [19]. However, in these works, prosumers and other flexible players can only interact with the real central entity to form an aggregation, and thus the benefits of direct interactions and negotiations among players are neglected. In fact, thanks to the help of smart-grid technologies, with which players are able to make in-time decisions and the market can be operated transparently with results broadcast promptly [20-21], prosumers and other flexible players do not have to rely on a real central entity to form an aggregation and pursue profitabilities in wholesale market.

In order to harvest benefits of aggregation to obtain revenues in wholesale market and encourage direct interactions among prosumers and other flexible players at the same time, this paper proposes an aggregation framework for prosumers based on TE, in which prosumers aggregate and trade in an independent, proactive and privacy-preserved manner without relying on a real central entity. The aggregation of prosumers as a whole acts as a retailer to participate in wholesale market and sell energy towards end-users in retail market. The problem is therefore generalized as a bi-level multi-leader multi-follower game, where prosumers are leaders and endusers are followers. The proposed TE based trading framework for prosumers is realized by an inner-outer iteration approach, in which the outer iteration achieves the retail price and optimal behaviors of the players, while the inner iteration is conducted during each time of the outer iteration solving end-users' optimal consuming profiles. The whole iteration process involves independent decision makings of players and only relies on the exchange of information of retail price and prosumers' offers instead of players' private information on detailed parameters and preferences for each appliance. To pay more attention to discussions of the proposed trading framework, this paper only considers the DA time scale with incorporating uncertainties of power generation and consumption as scenarios into the optimization problems. However, this approach can also be applied in the intra-day or RT market by addressing the optimization problems in a rolling horizon instead of the fixed 24-h DA horizon.

The organization of the paper is as follows. Section II describes the problem in detail. Then Section III formulates mathematical models for the bi-level multi-leader multifollower game. The inner-outer iteration approach to obtain the retail price and players' optimal behaviors is put forward in Section IV. Test cases and result analysis are conducted in Section V, and Section VI follows to conclude the paper.

\section{PROBLEM DESCRIPTION}

As shown in Fig. 1, the aggregation of prosumers as a whole acts as a retailer that purchases/sells energy at price of $\lambda_{t}^{D A}$ in 


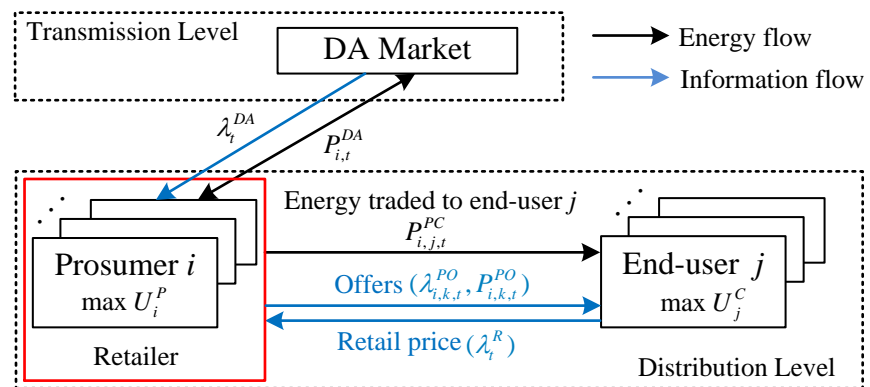

Fig. 1. Trading framework of TE based aggregation of prosumers.

DA market and sells energy to end-users at retail price of $\lambda_{t}^{R}$ . The objective of prosumer $i$ is to maximize its own revenue by identifying the optimal strategies in DA market $\left(P_{i, t}^{P}\right)$ and offers towards end-users $\left(\lambda_{i, k, t}^{P O}\right.$ and $\left.P_{i, k, t}^{P O}\right)$, while the objective of end-user $j$ is to maximize its own revenue by identifying the optimal consuming profiles, which affect the retail price and prosumers' revenues. Therefore, the proposed trading framework for prosumers is generalized as a bi-level multileader multi-follower game. The leaders represent optimization problems of prosumers, and the followers are characterized as optimization problems of end-users.

To realize the TE based trading framework for prosumers, in which players can trade in an independent, proactive, and privacy-preserved manner, an inner-outer iteration approach [22-23] is proposed to address the problem. The outer iteration involves interactions between prosumers (leaders) and end-users (followers), and converges to obtain final results including the retail price and optimal behaviors for all players. In the outer iteration, each prosumer independently decides on its own strategies and offers by solving their optimization problems with the retail price updated by the last time of iteration. Then end-users independently conduct the optimization problems to arrange their consuming profiles in an inner iteration process, and the retail price can be generated and updated with prosumers' offers and end-users' consuming profiles. With the updated retail price, each prosumer conducts its optimization problems again and adjusts its strategies and offers again, until no adjustment on the retail price is observed. As mentioned, during each time of the outer iteration, the rearrangement of end-users' consuming profiles are identified by an inner iteration process. In the inner iteration, prosumers' offers are fixed, while each end-user independently conducts its optimization problems and rearranges its consuming profiles with the retail price updated in the last time of inner iteration. The retail price is then generated again with endusers' rearranged consuming profiles and prosumers' offers, and end-users rearrange their consuming profiles again, until no adjustment on the retail price is observed.

Therefore, the inner-outer iteration process only relies on the exchange of information of the retail price and prosumers' offers instead of players' private information on detailed parameters and preferences for each appliance, and all players could independently participate in the formation of retail price. Furthermore, the prosumers proactively aggregate to behave as a retailer and pursue profitabilities in wholesale market, while both prosumers and end-users could benefit from flexibilities and self-generated energy of the aggregation. These attributes assure the independent, proactive and privacypreserved interactions for prosumers and end-users, as well as the harvest of benefits of aggregation in sharing flexibilities.

It is noted that the generation of retail price respects the merit order principle, i.e., prosumers' offers with the lowest offered price are adopted first and the retail price is set as the offered price of last unit of energy to satisfy end-users' consumptions [24]. Also note that uncertainty modeling is of great importance in electricity market. For instance, Hanif. et al. [25] incorporate the uncertainties in calculating robust DA distribution locational marginal prices through an iteration process. This paper deems that it is the players' own responsibilities to consider the uncertainties when making decisions, identical to current wholesale market mechanisms in most countries. Therefore, uncertainties of prosumers' generation, loads, EVs and DA market prices will be taken into account with a scenario-based approach [15][18] in optimizing players' behaviors, so the iteration process will not be much affected by the modeling of uncertainties.

As further discussed in Section III, since prosumers' offers are determined based on the cost of acquiring energy, the offered prices of prosumers would be lower than the DA market price when prosumers have surplus energy, and thus end-users could be benefited. When a prosumer has no surplus energy, it may choose to purchase energy in retail market on an equal basis with the end-users. Furthermore, as the merit order principle is adopted for the retail market, the retail price would be higher than offered prices of some prosumers, thus these prosumers could obtain extra revenues in retail market. The above attributes assure that the proposed trading framework is attractive to both prosumers and end-users.

\section{PROBlEM Formulation}

As described in Section II, the trading framework for prosumers is generalized as a bi-level multi-leader multifollower problem. The upper-level and lower-level problem solves prosumers' and end-users' optimization problems, respectively. The mathematical models of the bi-level problem are illustrated in this section.

For the sake of clarity, assume the prosumer-aggregated retailer is a price-taker in DA market, and all players are rational self-interested with their own objectives. Both prosumers and end-users are households, and their loads include 4 sorts of tasks, namely non-interruptible and non-deferrable tasks, interruptible and deferrable tasks, non-interruptible and deferrable tasks, and EVs. Prosumers are equipped with PV panels, so they have generation capabilities.

\section{A. End-user Lower-Level Problem}

For end-user $j$, the objective function is

$$
\max _{P_{j, t}^{C}} U_{j}^{C}=-\sum_{t} \lambda_{t}^{R} P_{j, t}^{C}
$$




$$
\begin{aligned}
& \text { s.t. } \quad P_{j, t}^{C}=P_{j, t}^{n i n d}+\sum_{n_{j}} P_{j, n_{j}, t}^{i d}+\sum_{m_{j}} P_{j, m_{j}, t}^{n i d}+P_{j, t}^{E V} \\
& \sum_{t} P_{j, n_{j}, t}^{i d}=E_{j, n_{j}}^{i d} \\
& P_{j, n_{j}, t}^{i d}=0 \text {, when } t \notin\left(t_{j, n_{j}}^{i d 1}, t_{j, n_{j}}^{i d 2}\right) \\
& 0 \leq P_{j, n_{j}, t}^{i d} \leq P_{j, n_{j}}^{i d, \max } \\
& u_{j, m_{j}, t}^{n i d} \in\{0,1\} \\
& u_{j, m_{j}, t}^{n i d}=0 \text {, when } t \notin\left(t_{j, m_{j}}^{n i d 1}, t_{j, m_{j}}^{n i d 2}\right) \\
& \sum_{t} u_{j, m_{j}, t}^{n i d}=1 \\
& P_{j, m_{j}, t}^{n i d}=\sum_{l} P_{j, m_{j}, l}^{n i d} u_{j, m_{j}, t}^{n i d} \\
& P_{j, t}^{E V}=P_{j, t}^{E V c}-P_{j, t}^{E V d} \\
& 0 \leq P_{j, t}^{E V c} \leq u_{j, t}^{E V c} P_{j, t}^{E V c, m} \\
& 0 \leq P_{j, t}^{E V d} \leq u_{j, t}^{E V d} P_{j, t}^{E V d, \max } \\
& u_{j, t}^{E V c}, u_{j, t}^{E V d} \in\{0,1\} \\
& u_{j, t}^{E V c}+u_{j, t}^{E V d} \leq 1 \\
& u_{j, t}^{E V c}=0, u_{j, t}^{E V d}=0 \text { when } t \in\left(t_{j}^{E V 1}, t_{j}^{E V 2}\right) \\
& D_{j, t}^{E V} \eta_{j}^{E V}=P_{j, t}^{E V u} \\
& E_{j, t}^{E V}=E_{j, t-1}^{E V}+\left(\eta_{j}^{E V c} P_{j, t}^{E V c}-\frac{P_{j, t}^{E V d}}{\eta_{j}^{E V d}}-P_{j, t}^{E V u}\right) \\
& E_{j}^{E V, \min } \leq E_{j, t}^{E V} \leq E_{j}^{E V, \max } \\
& E_{j, t_{0}}^{E V}=E_{j, t_{T}-1}^{E V}=E_{j}^{E V, i n i}
\end{aligned}
$$

The objective of end-user $j$ is to achieve the maximum revenue in purchasing energy, which is represented as the value of minus cost, as indicated in (1). The purchased energy equals the summation of energy consumed by 4 sorts of tasks, namely non-interruptible and non-deferrable tasks, interruptible and deferrable tasks, non-interruptible and deferrable tasks, and EVs, as denoted by (2). Constraints (3)-(5) are for interruptible and deferrable tasks. The overall energy consumption is constrained in (3). Constraint (4) denotes the starting and ending time of task $n_{j}$, and the maximum power consumption of task $n_{j}$ is limited in (5). Constraints (6)-(9) are for noninterruptible and deferrable tasks. Constraints (6)-(8) describe the binary representing the starting time of task $m_{j}$. This binary affects the power profiles of task $m_{j}$, as captured in (9), where $P_{j, m_{j}, l}^{n i d}$ indicates the predefined power profiles of the task. Constraints (10)-(15) restrict the charging/discharging of EV. The overall power consumption is calculated by the difference between charging power and discharging power, as indicated in (10). Constraints (11) and (12) limit the charging and discharging power. Constraints (13)-(15) describe the binaries representing the charging and discharging time, assuring charging and discharging do not occur in the same time or during driving time. Consumed power in driving is calculated in (16). State and constraints of battery are illustrated in (17)(19). Constraints (17) and (18) represent the energy state in battery, and constraint (19) limits its initial and final value.

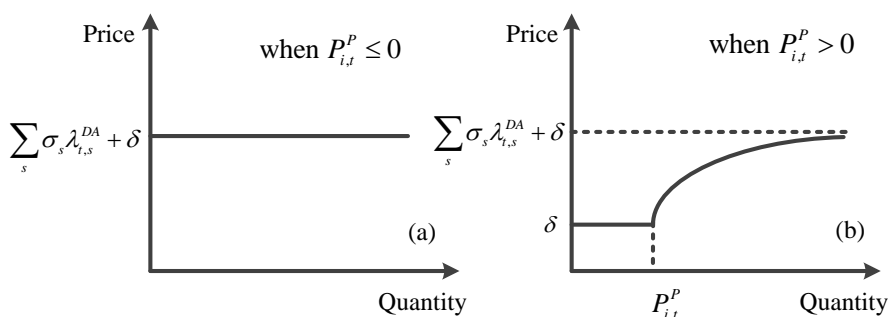

Fig. 2. Description of prosumers' offers.

\section{B. Prosumer Upper-Level Problem}

For prosumer $i$, the mathematical models are similar to those of end-users, except that prosumers have generation capabilities. Therefore, the objective function of prosumer $i$ is to achieve the maximum revenue in selling energy in DA market and retail market, represented as

$$
\begin{array}{ll} 
& \max _{P_{i, t}^{P}} U_{i}^{P}=\lambda_{t, s}^{D A} P_{i, t}^{D A}+\lambda_{t}^{R} P_{i, t}^{P} \\
\text { s.t. } & P_{i, t}^{P}=P_{i, t}^{P G}-P_{i, t}^{D A} \\
& -\left(P_{i, t}^{P n i n d}+\sum_{n_{i}} P_{i, n_{i}, t}^{P i d}+\sum_{m_{i}} P_{i, m_{i}, t}^{P n i d}+P_{i, t}^{E V}\right)
\end{array}
$$

The constraints for the 4 sorts of tasks of the prosumer are similar to those of end-users, as illustrated in (3)-(19). Constraint (21) calculates the surplus energy as the difference between energy produced, and the summation of energy sold in DA market and energy consumed by 4 sorts of tasks. Note that when a prosumer has no surplus energy, it can purchase energy either in DA market or from other prosumers in retail market by behaving as an end-user, thus both $P_{i, t}^{D A}$ and $P_{i, t}^{P}$ can be negative.

\section{Prosumers' Offers}

As a retailer, prosumers can acquire energy from either self-generation or DA market. Hence, prosumers' offers are generated based on the cost of acquiring energy. Assume the offered price equals the cost of acquiring energy plus a constant revenue $\delta$, which compensates for the operation cost as a retailer. For prosumer $i$, the offers are

$$
\lambda_{i, t}^{P O}=\left\{\begin{array}{l}
\lambda_{t, s}^{D A}+\delta, \text { if } P_{i, t}^{P} \leq 0 \\
\delta, \text { if } 0 \leq P_{i, t}^{P O}<P_{i, t}^{P} \\
\lambda_{t, s}^{D A}\left(1-\frac{P_{i, t}^{P}}{P_{i, t}^{P O}}\right)+\delta, \text { if } 0<P_{i, t}^{P} \leq P_{i, t}^{P O}
\end{array}\right.
$$

The Fig. 2 further describes the offers. When the prosumer has no surplus energy, the cost of providing energy to endusers equals the price in DA market, represented as the first function in (22) and shown as Fig. 2(a). Fig. 2(b) shows the condition where the prosumer has surplus energy. When the prosumer's offered quantity is smaller than the surplus energy, the cost of providing the offered quantity equals the generation cost of self-owned generators by the prosumer, which equals zero in this paper since prosumers are only equipped with PV panels as generation capabilities. This case is indicated 
as the second function in (22). When the offered quantity exceeds the surplus energy, the part of the offered quantity lower than the surplus energy is acquired at price of zero, while the other part is acquired at the price in DA market. This case is denoted by the third function in (22). Equation (22) is non-linear but can be transformed to piecewise linearized expressions, as illustrated in (23)-(25). On one hand, the piecewise linearization makes the problem more tractable. On the other hand, piecewise offers are more common in electricity market [26-27].

$$
\begin{array}{ll} 
& \lambda_{i, t}^{P O}=\sum_{k} a_{i, k, t} P_{i, k, t}^{P O}+\delta \\
\text { s.t. } & 0 \leq P_{i, k, t}^{P O} \leq \triangle_{i, k, t} \\
& a_{i, k, t}=\frac{\left.\lambda_{i, t}^{P O}\right|_{P_{i, k-1, t}^{P O}+\triangle_{i, k, t}}-\left.\lambda_{i, t}^{P O}\right|_{P_{i, k-1, t}^{P O}}}{\triangle_{i, k, t}}
\end{array}
$$

where $\triangle_{i, k, t}$ represents the length of piece $k$ for prosumer $i$ in hour $t$ in the piecewise linearization.

\section{The InNer-OUter ITERATION APPROACH}

To realize the TE based aggregation framework for prosumers, an inner-outer iteration approach is proposed to address the bi-level multi-leader multi-follower problem. This section describes the approach in detail and discusses the convergence issue.

\section{A. Details of the Inner-Outer Iteration Approach}

The Fig. 3 depicts the inner-outer iteration approach, which consists of 4 steps, digested as follows.

Step 1. Initialize the retail price as the constant revenue $\delta$ in the first time of iteration.

Step 2. Each prosumer conducts its optimization problems illustrated in Subsection III-B and decides on its optimal trading strategies, then generates the offers according to (22).

Step 3. With the retail price, each end-user independently determines its consuming profiles by solving the optimization problems illustrated in Subsection III-A. The retail price is then calculated and updated with end-users' consuming profiles and prosumers' offers based on the merit order principle, as represented by (26)-(28).

$$
\begin{aligned}
& \min _{P_{i, j, t}^{P C}} \sum_{i, j, t} \lambda_{i, t}^{P O} P_{i, j, t}^{P C} \\
\text { s.t. } & \sum_{i, j} P_{i, j, t}^{P C}=\sum_{j} P_{j, t}^{C}-\sum_{i} \min \left(P_{i, t}^{P}, 0\right) \quad: \quad \lambda_{t}^{R} \\
& \sum_{i} P_{i, j, t}^{P C}=P_{j, t}^{C}
\end{aligned}
$$

The objective is to minimize the total costs in purchasing energy from prosumers, as shown in (26). Equations (27) and (28) constrain the total traded energy and energy traded towards end-user $j$, respectively. The retail price equals the dual variable of constraint (27). Note that the second item at the right hand side of (27) represents for energy purchased

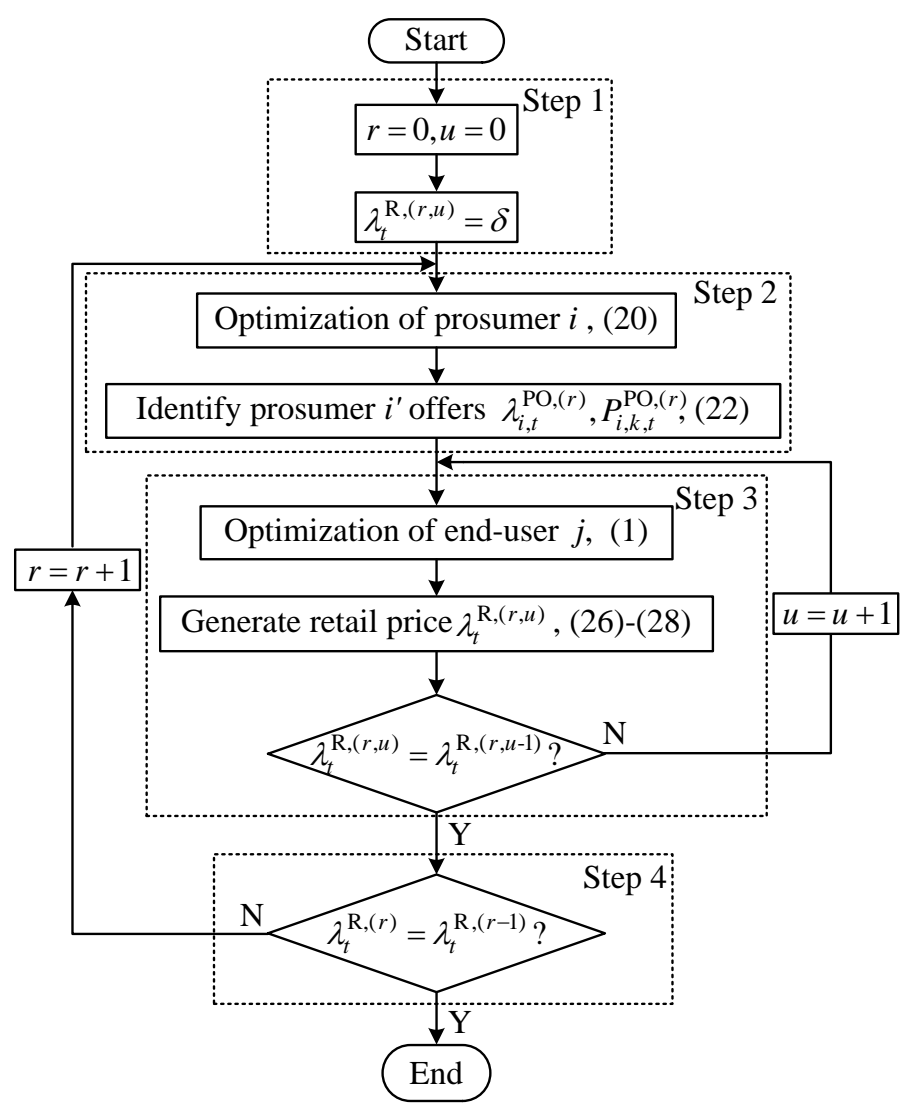

Fig. 3. The inner-outer iteration approach.

by prosumers in retail market. As explained in Subsection III$\mathrm{B}$, when a prosumer has no surplus energy, it may need to purchase energy from the retail market, equally as an end-user. However, the value of this item is determined by Step 2 and before conducting the optimization problems for generating retail price, so problems (26)-(28) are still linear and tractable.

With the updated retail price, end-users conduct their optimization problems again and rearrange their consuming profiles, then the retail price will be updated again based on (26)-(28), until no adjustment on the retail price is observed. The Step 3 corresponds to the inner iteration.

Step 4. When the retail price is set by the inner iteration, it is broadcast to the prosumers. If the retail price in $r$ th time of outer iteration does not equal that in the $r-1$ th time of outer iteration, go back to Step 2, and prosumers adjust their strategies and offers again based on the updated retail price. Otherwise, the iteration terminates, and the final results are obtained. The Steps 2 to 4 correspond to the outer iteration.

Therefore, the inner-outer iteration process only relies on the information exchange of the retail price and prosumers' offers instead of players' detailed parameters and preferences for each appliance, thus the players' privacy is preserved. During the iteration process, all the players could independently decide on their own behaviors by solving the optimization problems, and proactively participate in the formation of retail price. Furthermore, prosumers aggregate to behave as a retailer and pursue profitabilities in wholesale market, while both prosumers and end-users could benefit from flexibilities and 
self-generated energy of the aggregation on an equal basis. These attributes assure the independent, proactive and privacypreserved interactions for prosumers and end-users, as well as the harvest of benefits of aggregation in sharing flexibilities.

\section{B. Issue of Convergence}

In the inner iteration, the retail price is formed to balance supply and demand. In hours when the retail price is relatively low, end-users would shift load to these hours and the retail price will increase. On the contrary, in hours when the retail price is relatively high, end-users would shift load to other hours and the retail price will decrease. Since the end-users' consuming profiles vary with the retail price, oscillations may occur during iterations in a dilemma between two situations, 1) lower retail price and higher consumed energy; 2) higher retail price and lower consumed energy. Considering the nonlinear and non-analytical nature of the models, it is difficult to ensure the optimality and convergence. Borrowing the idea from [28], the converged result is selected as the situation in which end-users achieve higher revenues. The oscillations in the outer iteration can be handled identically, where the prosumers adjust their strategies and offers with the updated retail price. In this way, prosumers' strategies and offers can be uniquely determined as the revenue is maximized during the iteration process.

The problem is generalized as a multi-player game where all players only care for maximizing their own revenues during the whole iteration process. In the last time of iteration, the retail price is not altered, which means players no longer change their trading strategies or consuming profiles. These attributes justify when the converged solution is achieved, no player has unilateral incentive to deviate.

\section{CAse Study}

\section{A. Data and Approach}

In this section, the feasibility and effectiveness of the proposed TE based aggregation framework for prosumers are numerically analyzed in a 24-hr. period. The case consists of 50 prosumers and 50 end-users, which are assumed to be households equipped with all the appliances and randomly one type of EV listed in the Appendix, where detailed parameters of household appliances and EVs are acquired from [7, 29-30], and the driving patterns for EVs are randomly generated based on statistical data from the National Travel Survey in the U.K. [31]. The Gaussian distribution is adopted to consider different preferences of staring/ending time of load tasks for different players, with the averaged and standard deviation values listed in the Appendix. The power output of PV generation can be calculated as [32]

$$
P_{i, t}^{P G}=\eta^{P G} S_{i}^{P G} W_{t}\left(1-0.005\left(T_{t}-25\right)\right)
$$

where $\eta^{P G}, S_{i}^{P G}, W_{t}$ and $T_{t}$ represent conversion coefficient, array areas $\left(\mathrm{m}^{2}\right)$ of PV panel for prosumer $i$, solar irradiance $\left(\mathrm{W} / \mathrm{m}^{2}\right)$ in hour $t$ and the ambient temperature $\left({ }^{\circ} \mathrm{C}\right)$ in hour $t$. Relevant data are obtained in [33], where the conversion coefficient $\eta^{P G}$ and the ambient temperature are set as $15.7 \%$ and $25^{\circ} \mathrm{C}$, respectively. The array areas of the 50 prosumers

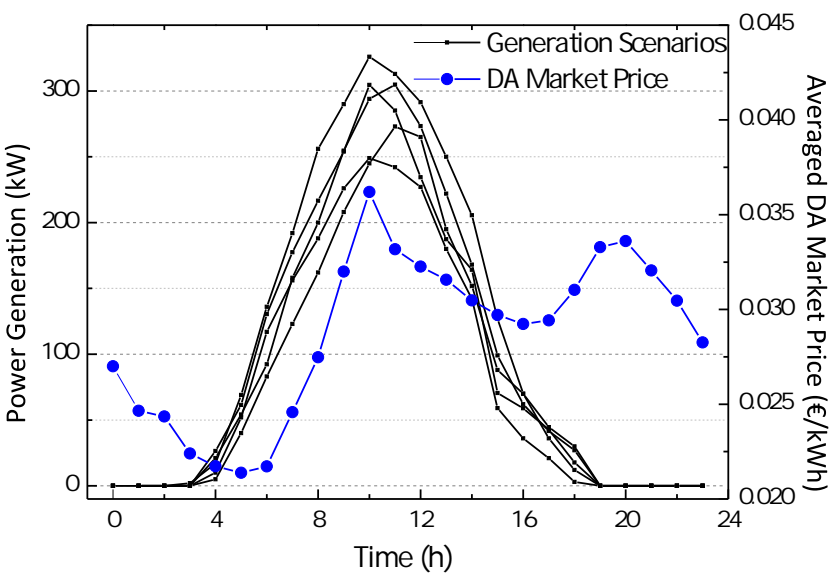

Fig. 4. Overall power generation scenarios and averaged DA market price.

are assumed to obey a uniform distribution with the minimum value of $20 \mathrm{~m}^{2}$ and maximum value of $50 \mathrm{~m}^{2}$. The Gaussian distribution is adopted to illustrate uncertainties of the solar irradiance for the community with a standard deviation of $10 \%$ of the averaged value, and the averaged value for each time period is retrieved from [33] with a maximum value of $900 \mathrm{~W} / \mathrm{m}^{2}$ occurring in hour 11.

To consider the uncertainties of players' power generation and consumption, the Monte Carlo method is employed to generate 1000 scenarios for PV power generation and consuming parameters of load tasks and EVs with the even probability $(1 / 1000)$. The fast-forward reduction algorithm is then adopted to reduce the original 1000 scenarios to 5 scenarios [34]. The DA market prices of DK2 district in Nordic market in April of 2017 are adopted as scenarios for the DA price [35]. Fig. 4 shows the scenarios of overall PV power generation of the 50 prosumers as well as the averaged DA market price. Note that the PV power generation is zero before hour 3 or after hour 19. The constant revenue of selling per-unit energy $\delta$ is set to $0.015 € / \mathrm{kWh}$.

In order to illustrate the effectiveness of the proposed trading framework, three cases are studied for comparison.

Case 1: The proposed TE based aggregation framework for prosumers. In this case, since direct interactions are allowed among prosumers and end-users, all the players can be benefited from the flexibilities and self-generated energy of the aggregation on an equal basis.

Case 2: A real retailer exists and all players can only trade with the retailer with a fixed retail price, based on which players solve their optimization problems and decide on their optimal behaviors. For the sake of comparison, the same constant revenue $\delta$ is still employed for the real retailer to compensate for operation cost of being a retailer, thus the retail price of selling energy to prosumers/end-users is set as $\sum_{s} \sigma_{s} \lambda_{t, s}^{D A}+\delta$, while the retail price of purchasing energy from prosumers is set as $\sum_{s} \sigma_{s} \lambda_{t, s}^{D A}-\delta$. In this case, only the real retailer takes advantages of the flexibilities and selfgenerated energy of the aggregation as no direct interactions are allowed among prosumers and end-users.

Case 3: A real central entity exists to optimize the prosumers' behaviors in a centralized manner with the objective 


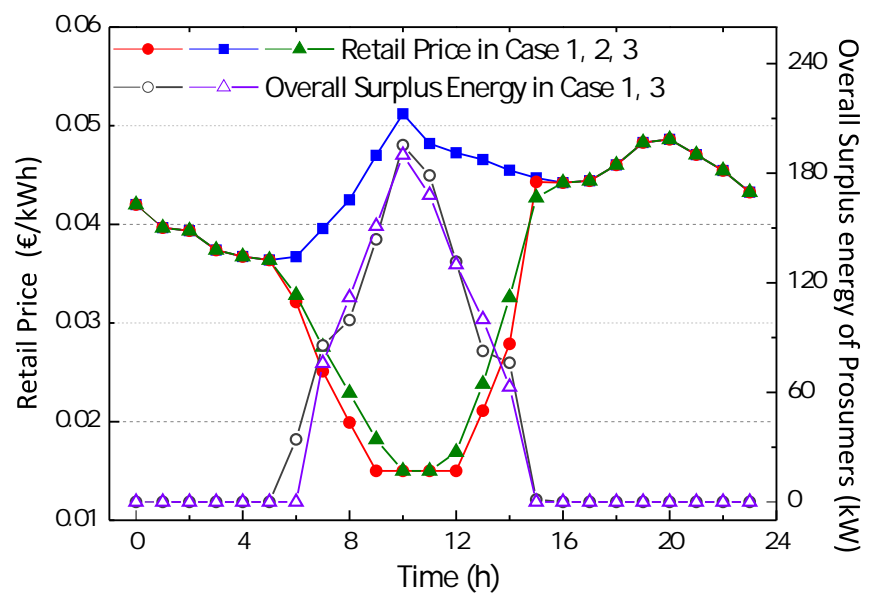

Fig. 5. Retail price and overall surplus energy of prosumers.

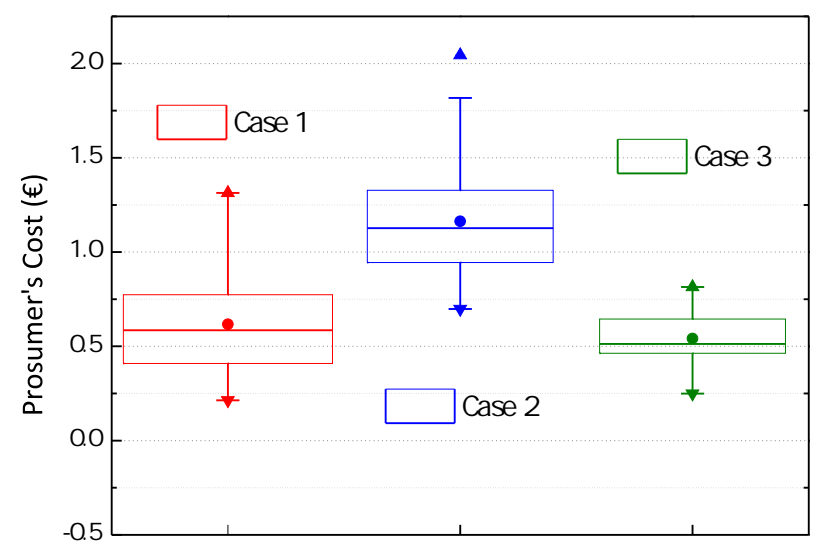

Fig. 6. Prosumer's cost.

to achieve the maximum revenue for the whole aggregation by collecting detailed parameters and preferences for each appliance of prosumers, while the prosumers as an aggregation still behave as a retailer to sell energy to end-users. The retail price is generated by interactions between the aggregation of prosumers and end-users. In this case, the prosumers mainly take advantages of the flexibilities and self-generated energy of the aggregation via the centralized optimization, since endusers are only allowed to interact with the aggregation instead of the individual prosumers.

\section{B. Retail Price}

The Fig. 5 shows the overall surplus energy of prosumers and compares the retail prices in Cases 1,2 and 3. As shown by the black and purple lines, the quantity of overall surplus energy over the 24-hr. period is $1029.13 \mathrm{kWh}$ in Case 1 and $990.87 \mathrm{kWh}$ in Case 3. The quantity of overall surplus energy is less in Case 3 due to the centralized optimization of prosumers, implying that a prosumer enjoys the priority over end-users to purchase other prosumers' surplus energy within the aggregation. However, prosumers and end-users purchase energy in retail market on an equal basis in Case 1.

As the quantity of overall surplus energy is greater, the retail price is lower in Case 1 than in Case 3. Furthermore, the retail prices in Cases 1 and 3 are much lower than that in Case 2 in

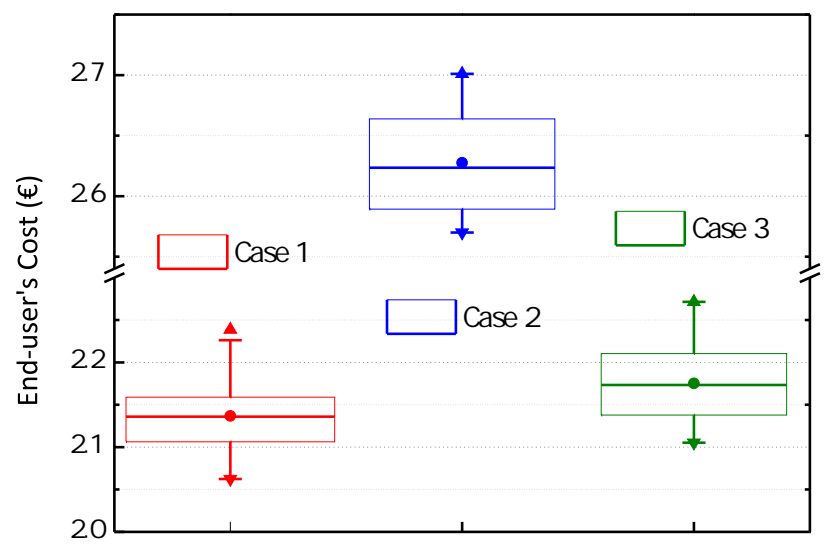

Fig. 7. End-user's cost.

hours when the quantity of overall surplus energy exceeds 0 , because prosumers' offered price in retail market is no higher than the price in DA market, according to (22) in Subsection III-C. To be specific, in hours 9-12 for Case 1 or hours 1011 for Case 3 when prosumers offer more energy than endusers consume, the retail price decreases to $0.015 € / \mathrm{kWh}$ that only compensates for the prosumers as a retailer. These results indicate that the proposed TE based trading framework could decrease the retail price and assure the fairness in purchasing energy for both prosumers and end-users.

\section{Player's Revenue}

Both prosumers' and end-users' revenues over the 24-hr. period in these cases are negative values, so their costs are compared for the sake of convenience. As shown in Figs. 6 and 7 , the circle dot indicates the average value and the triangle dot represents the maximum/minimum value, while the box includes the values from the first to the third quartile. The prosumer's cost on average is $0.62 €, 1.16 €$ and $0.55 €$ in Cases 1, 2 and 3, respectively. Compared to Case 2, the averaged cost reductions for prosumers in Cases 1 and 3 are $0.54 €$ and $0.61 €$, stemming from two reasons. First, prosumers do not have to pay the constant revenue $\delta$ to the real retailer for purchasing per unit of energy, instead, they could obtain the constant revenue $\delta$ for selling per unit of energy in retail market. This can be calculated with the quantity of energy traded by prosumers and accounts for $0.33 €$ and $0.31 €$ in the total cost reductions for Cases 1 and 3, respectively. Second, prosumers could take advantages of flexibilities and selfgenerated energy of other players more efficiently via direct interactions so as to further reduce the costs in wholesale market. This accounts for $0.21 €$ and $0.30 €$ in the total cost reductions for Cases 1 and 3, respectively. As shown in Fig. 6 , the distribution range of the prosumer's cost is smaller in Case 3, as prosumers' behaviors are optimized in a centralized manner. Thanks to the decreased retail price, the end-user's costs on average in Cases $1(2.14 €)$ and $3(2.18 €)$ are lower than the cost in Case $2(2.63 €)$, as demonstrated in Fig. 7. The end-users obtain the highest cost reduction in Case 1 as they are able to benefit from the flexibilities of the aggregation on an equal basis with the prosumers. 


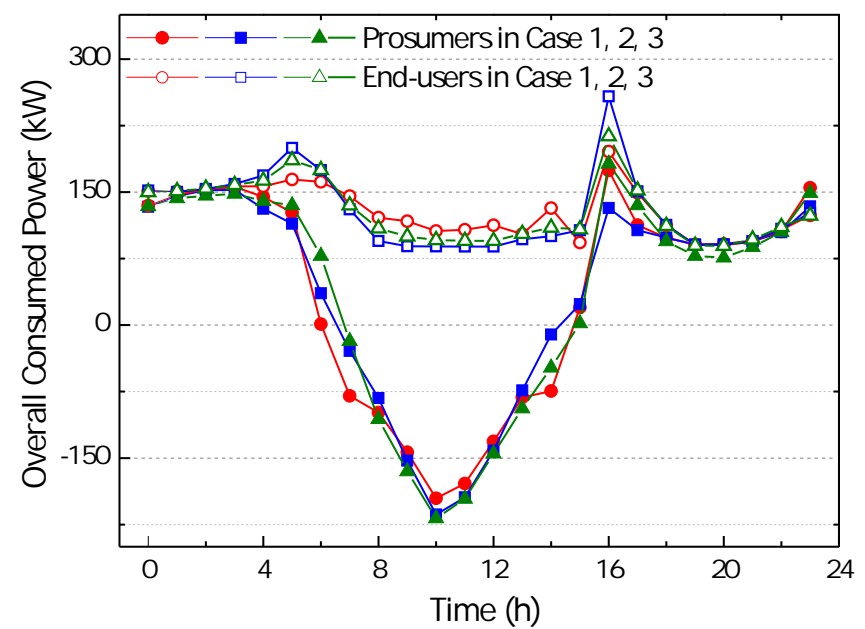

Fig. 8. Overall consumed power of players.

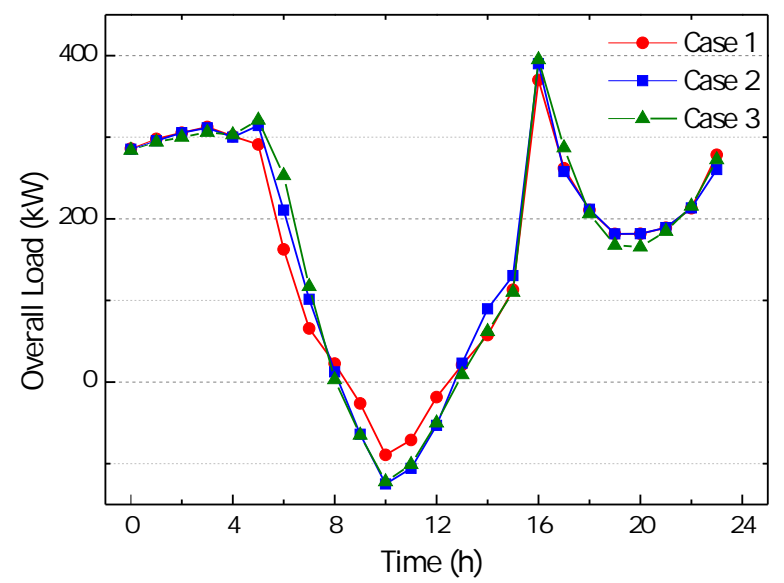

Fig. 9. Overall load of all players.

These results indicate that both prosumers and end-users could enjoy cost reductions in Cases 1 and 3 compared to Case 2. On one hand, prosumers do not have to pay the constant revenue to a real retailer as they behave as the retailer themselves. On the other hand, both prosumers and end-users are able to participate in the formation of retail price, so they could take advantages of flexibilities and self-generated energy of the aggregation more efficiently, thus their energy purchasing costs in wholesale market are further reduced.

\section{Overall Load}

The Fig. 8 indicates the consumed power of prosumers and end-users in 3 cases. The end-users' consuming profiles are smoother in Case 1. To be specific, the peak load in Case 1 occurring in hour 16 is $195.68 \mathrm{~kW}$, lower than that in Cases $2(258.03 \mathrm{~kW})$ and $3(213.72 \mathrm{~kW})$. The Fig. 9 further demonstrates the overall load of all players, and the peak load in Case 1 occurring in hour 16 is $370.07 \mathrm{~kW}$, lower than that in Cases $2(390.03 \mathrm{~kW})$ and $3(395.91 \mathrm{~kW})$. These results indicate that the overall peak load of the whole community can be reduced with the proposed TE based trading framework for prosumers.

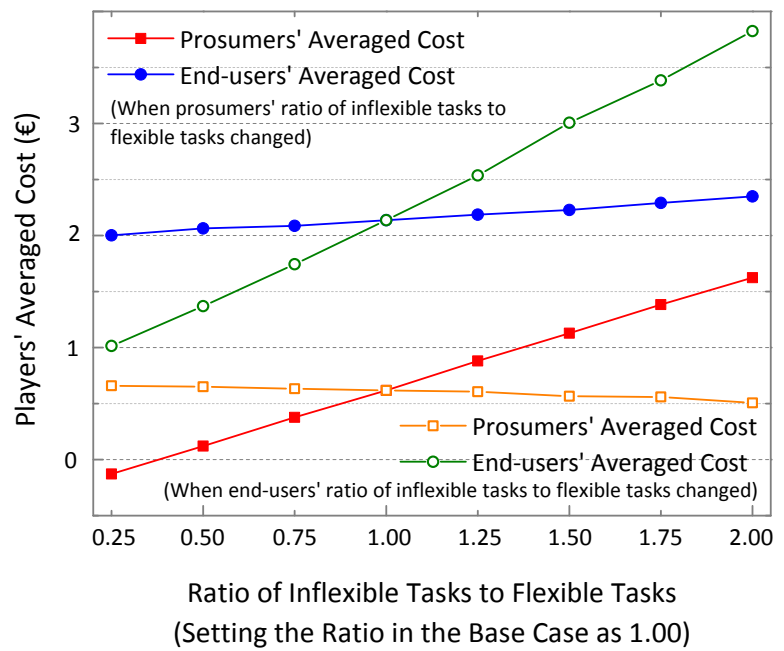

Fig. 10. Players' averaged cost vs. ratio of inflexible tasks to flexible tasks compared to the Base Case.

\section{E. Influence of the task composition}

The interruptible and deferrable tasks, the non-interruptible and deferrable tasks, and the EVs are collectively named as the flexible tasks here, while the non-interruptible and nondeferrable tasks are referred to as inflexible tasks. For the sake of comparison, set the ratio of energy consumed by inflexible tasks to energy consumed by flexible tasks in the above Case 1 as the Base Case, namely 1.00 in Figs. 10 and 11. With the overall energy consumed by the 4 sorts of tasks unchanged, the ratio is adjusted to study the influences of players' task composition on the market results, as demonstrated in Figs. 10 and 11. As indicated by the red and blue lines in Fig. 10 and the red line in Fig. 11, when prosumers' ratio of inflexible tasks to flexible tasks increases and thus prosumers' flexibilities decrease, both prosumers' and end-users' averaged costs are elevated. This occurs because less flexibility in prosumers' tasks brings about less utilization of their selfgenerated energy, which is cheaper than energy acquired in wholesale market. As a result, the retail price rises and endusers' averaged cost increases correspondingly. On the other hand, as indicated by the orange and green lines in Fig. 10 and the blue line in Fig. 11, when end-users' ratio of inflexible tasks to flexible tasks increases and thus end-users' flexibilities decrease, end-users' averaged cost rises up since less prosumers' self-generated energy can be utilized by endusers. Hence, more self-generated energy will be adopted by prosumers themselves, leading to a reduction on prosumers' averaged cost and an increase in the retail price. These results indicate the proposed TE based trading framework could encourage the players to improve their flexibilities to obtain greater revenues.

\section{F. Computational issues}

With regard to computational issues, the problem is implemented on $\mathrm{C}++$ and the related MILP problems are solved by CPLEX, on a laptop with an Intel Core i7 3.60GHz CPU and 8GB of RAM. 


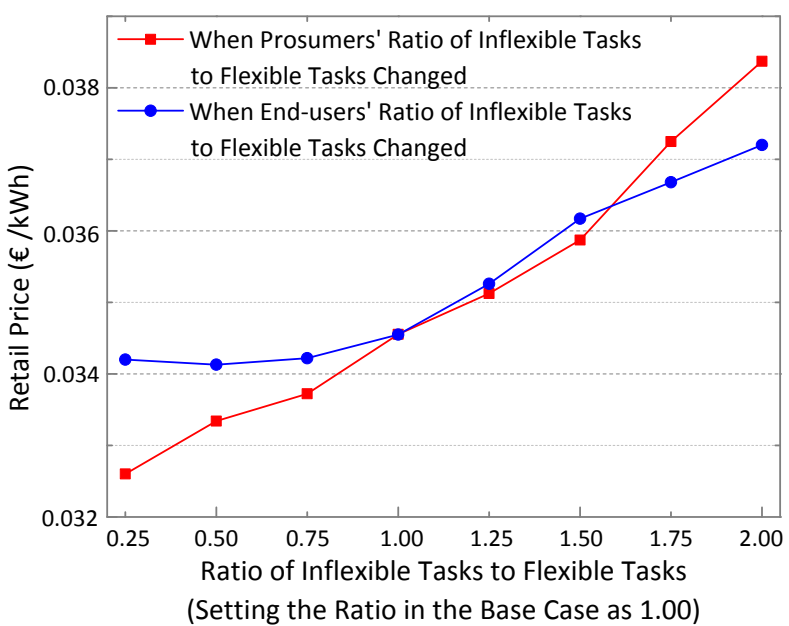

Fig. 11. Averaged retail price vs. ratio of inflexible tasks to flexible tasks compared to the Base Case.

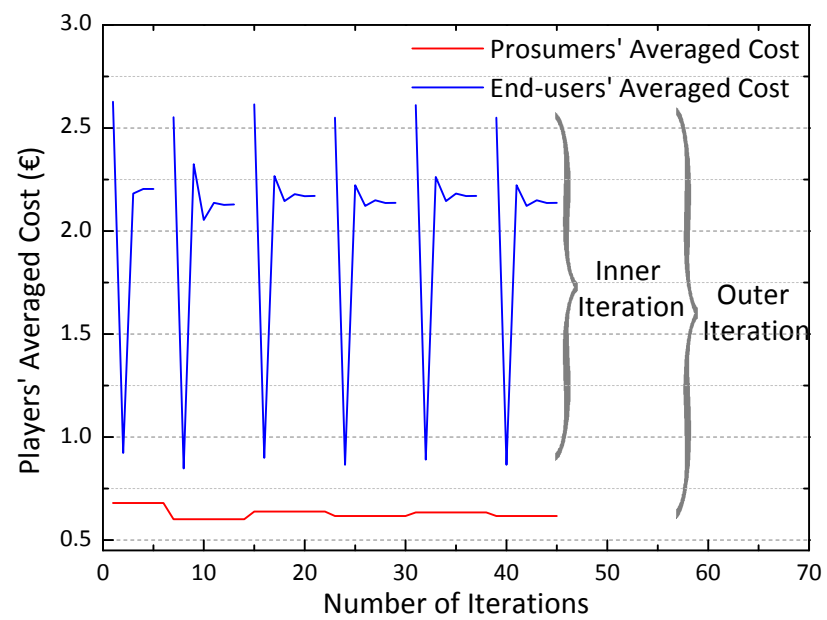

Fig. 12. Convergence plot.

The convergence plot is shown in Fig. 12. The player's averaged cost is illustrated to show the convergence plot. As can be seen, an oscillation occurs in the outer iteration. As stated in Section IV-B, the converged result is then selected as the situation where prosumers achieve higher revenues.

The running time of the problem is $3.7 \mathrm{~s}$ with the current size of players. When the population of players grows by 5 to 10 times, the time that the algorithm takes to converge to a solution would be $26.6 \mathrm{~s}$ to $100.3 \mathrm{~s}$.

\section{CONCLUSION}

As prosumers proliferate with the rapid growth of distributed energy resources, efficient trading frameworks to accommodate prosumers and promote their profitabilities are highly anticipated. In order to harvest benefits of aggregation to obtain revenues in wholesale market and encourage direct interactions among prosumers and other flexible players at the same time, this paper proposes an TE based aggregation framework for prosumers, in which prosumers aggregate and trade in an independent, proactive and privacy-preserved manner without relying on a real central entity, while other flexible players could also be benefited on an equal basis. The aggregation of prosumers as a whole behaves as a retailer, who trades both in wholesale market and towards end-users in retail market. Since prosumers' optimal strategies are dependent with the retail price which would be affected by end-users' consuming profiles, the problem is generalized as a bi-level multi-leader multi-follower game where prosumers are leaders and endusers are followers. To realize the independent, proactive and privacy-preserved interactions among prosumers and endusers, an inner-outer iteration approach is proposed, in which the outer iteration achieves the final results including the retail price and optimal behaviors of players, while the inner iteration is conducted during each time of the outer iteration solving end-users' optimal consuming profiles. The whole iteration process involves independent decision makings of players and only relies on the exchange of information of retail price and prosumers' offers instead of players' private information such as detailed parameters and preferences for each appliance. Case studies are then conducted to justify the applicability and effectiveness of the proposed TE based trading framework for prosumers, indicating that by enabling the direct interactions among prosumers and end-users on an equal basis, the proposed trading framework leads to a lower retail price, increased revenues for both prosumers and endusers, and a reduced peak load.

Future work may include assuring and improving the secure and reliable operation of the distribution networks through designing and operation of the retail market in the context of rapid growth of prosumers and enhanced application of TE.

\section{APPENDIX}

The data regarding the four sorts of tasks of players are illustrated in Tables I to V.

TABLE I: Data on non-interruptible and non-deferrable tasks

\begin{tabular}{l|ll}
\hline \hline Task & Power $(\mathrm{kW})$ & Total usage period $(\mathrm{h})$ \\
\hline Refregerator & 1.667 & 24 \\
Telephone & 0.005 & 24 \\
Others & 0.050 & 24 \\
\hline \hline
\end{tabular}

TABLE II: Data on interruptible and deferrable tasks

\begin{tabular}{l|lllll}
\hline \hline Task & $\begin{array}{l}\text { Power } \\
(\mathrm{kW})\end{array}$ & $\begin{array}{l}\text { Total } \\
\text { usage } \\
\text { period } \\
\text { (h) }\end{array}$ & $\begin{array}{l}\text { Averaged Averaged Standard } \\
\text { start- } \\
\text { ing } \\
\text { time }\end{array}$ & $\begin{array}{l}\text { ending } \\
\text { time }\end{array}$ & $\begin{array}{l}\text { deviation } \\
\text { of start- } \\
\text { ing/finishing } \\
\text { time (h) }\end{array}$ \\
\hline Dishwasher & 1.32 & 0.50 & $20: 00$ & $22: 45$ & 3.0 \\
AC & 1.20 & 7.25 & $12: 00$ & $08: 30$ & 3.0 \\
Oven & 1.20 & 0.50 & $19: 00$ & $20: 45$ & 1.0 \\
Iron & 1.20 & 0.50 & $19: 00$ & $19: 45$ & 1.0 \\
Kettle & 1.00 & 0.50 & $06: 45$ & $07: 45$ & 2.5 \\
Hairdryer & 0.90 & 0.25 & $20: 30$ & $21: 30$ & 2.5 \\
Microwave & 0.20 & 0.25 & $18: 45$ & $20: 00$ & 1.5 \\
Toaster & 0.20 & 0.25 & $07: 15$ & $08: 30$ & 2.0 \\
Others & 0.12 & 0.50 & $00: 00$ & $24: 00$ & 3.0 \\
\hline \hline
\end{tabular}


TABLE III: Data on non-interruptible and deferrable tasks

\begin{tabular}{l|lllll}
\hline \hline Task & $\begin{array}{l}\text { Power } \\
(\mathrm{kW})\end{array}$ & $\begin{array}{l}\text { Total } \\
\text { usage } \\
\text { period } \\
\text { (h) }\end{array}$ & $\begin{array}{l}\text { Averaged Averaged Standard } \\
\text { ear- } \\
\text { liest } \\
\text { start- } \\
\text { ing } \\
\text { time } \\
\text { lh) }\end{array}$ & $\begin{array}{l}\text { latest } \\
\text { start- } \\
\text { ing } \\
\text { time } \\
\text { (h) }\end{array}$ & $\begin{array}{l}\text { deviation } \\
\text { of earliest } \\
\text { starting } \\
\text { time (h) }\end{array}$ \\
& & & & \\
& & & & & \\
\hline $\begin{array}{l}\text { Washing } \\
\text { machine }\end{array}$ & 1.40 & 1.00 & $09: 00$ & $21: 30$ & 1.5 \\
Computer & 0.15 & 2.25 & $09: 00$ & $23: 00$ & 2.0 \\
TV & 0.09 & 6.75 & $10: 00$ & $23: 30$ & 3.0 \\
Others & 0.09 & 3.00 & $00: 00$ & $24: 00$ & 3.0 \\
\hline \hline
\end{tabular}

TABLE IV: Data on EVs

\begin{tabular}{|c|c|c|c|c|c|}
\hline $\begin{array}{l}\text { EV } \\
\text { types }\end{array}$ & $\begin{array}{l}\text { Capacity } \\
(\mathrm{kWh})\end{array}$ & $\begin{array}{l}\text { Maximum } \\
\text { charg- } \\
\text { ing } \\
\text { power } \\
(\mathrm{kW})\end{array}$ & $\begin{array}{l}\text { Maximum } \\
\text { dis- } \\
\text { charg- } \\
\text { ing } \\
\text { power } \\
(\mathrm{kW})\end{array}$ & $\begin{array}{l}\text { Efficiency } \\
\text { of } \\
\text { energy } \\
\text { over } \\
\text { dis- } \\
\text { tance } \\
\text { (k- } \\
\text { Wh/km) }\end{array}$ & $\begin{array}{l}\text { Charging } \\
\text { /Dis- } \\
\text { charg- } \\
\text { ing } \\
\text { effi- } \\
\text { ciency }\end{array}$ \\
\hline 1 & 30 & 4.8 & 4.1 & 0.21 & $0.95 / 0.9$ \\
\hline 2 & 40 & 6.4 & 5.5 & 0.24 & $0.95 / 0.9$ \\
\hline
\end{tabular}

TABLE V: Data on driving patterns

\begin{tabular}{llll}
\hline \hline & $\begin{array}{l}\text { Driving } \\
\text { distance }(\mathrm{km})\end{array}$ & $\begin{array}{l}\text { Departure } \\
\text { time }(\mathrm{h})\end{array}$ & $\begin{array}{l}\text { Arrival } \\
\text { time }(\mathrm{h})\end{array}$ \\
\hline $\begin{array}{l}\text { Averaged } \\
\text { value }\end{array}$ & 28.9 & $08: 30$ & $17: 30$ \\
\hline $\begin{array}{l}\text { Standard } \\
\text { deviation }\end{array}$ & 12.7 & 2.0 & 2.0 \\
\hline \hline
\end{tabular}

\section{REFERENCES}

[1] Y. Parag, and B. Sovacool, "Electricity market design for the prosumer era," Nature Energy, vol. 1, pp. 1-6, Mar. 2016.

[2] P. Silva, D. Ilic, and S. Karnouskos, "The impact of smart grid prosumer grouping on forecasting accuracy and its benefits for local electricity market trading," IEEE Trans. Smart Grid, vol. 5, pp. 402-410, Jan. 2014.

[3] J. Qiu, J. Zhao, H. Yang, and Z.Y. Dong, "Optimal scheduling for prosumers in coupled transactive power and gas systems," IEEE Trans. Power Syst., vol. 33, pp. 1970-1980, Mar. 2018.

[4] G. Rahi, S. Etesami, W. Saad, N. Mandayam, and H. Poor, "Managing price uncertainty in prosumer-centric energy trading : a prospect-theoretic Stackelberg game approach," IEEE Trans. Smart Grid, vol. 10, pp. 702713, Jan. 2019.

[5] K. Kok, and S. Widergren, "A society of devices: integrating intelligent distributed resources with transactive energy," IEEE Power and Energy Mag., vol. 14, pp. 34-45, May/Jun. 2016.

[6] S. Chen, and C. Liu, "From demand response to transactive energy: state of the art," J. of Mod. Power Syst. and Clean Energy, vol. 5, pp. 10-19, Jan. 2017.

[7] Y. Xiao, X. Wang, P. Pinson, and X. Wang, "A local energy market for electricity and hydrogen," IEEE Trans. Power Syst., vol. 33, pp. 3898-3908, Jul. 2018.
[8] F. Lezama, J. Soares, P. Hernandez-Leal, M. Kaisers, T. Pinto, and Z. Vale, "Local energy markets: paving the path toward fully transactive energy systems," IEEE Trans. Power Syst., vol. 34, pp. 4081-4088, Sep. 2019.

[9] T. Sousa, T. Soares, P. Pinson, F. Moret, T. Baroche, and E. Sorin, "Peer-to-peer and community-based markets: a comprehensive review," Renewable and Sustainable Energy Reviews, vol. 104, pp. 367-378, Jan. 2019.

[10] T. Morstyn, and M. McCulloch, "Multiclass energy management for peer-to-peer energy trading driven by prosumer preferences," IEEE Trans. Power Syst., vol. 34, pp. 4005-4014, Sep. 2019.

[11] E. Sorin, L. Bobo, and P. Pinson, "Consensus-based approach to peer-topeer electricity markets with product differentiation," IEEE Trans. Power Syst., vol. 34, pp. 994-1004, Mar. 2019.

[12] Powerpeers, Energie van elkaar [Online]. Available: https://www.powerpeers.nl/.

[13] M. Song, and M. Amelin, "Purchase bidding strategy for a retailer with flexile demands in day-ahead electricity market," IEEE Trans. Power Syst., vol. 32, pp. 1839-1850, May. 2017.

[14] Q. Wang, C. Zhang, J. Wang, P. Pinson, and J. Ostergaard, "Real-time trading strategies of proactive DISCO with heterogeneous DG owners," IEEE Trans. Smart Grid, vol. 9, pp. 1688-1697, Aug. 2016.

[15] C. Zhang, Q. Wang, J. Wang, J. Morales, P. Pinson, and J. Ostergaard, "Real-time procurement strategies of a proactive disctribution company with aggregator-based demand response," IEEE Trans. Smart Grid, vol. 9, pp. 766-776, May. 2016.

[16] Y. Gong, Y. Cai, Y. Guo, and Y. Fang, "A privacy-preserving scheme for incentive-based demand response in the smart grid," IEEE Trans. Smart Grid, vol. 7, pp. 1304-1313, May. 2016.

[17] C. Rottondi, G. Verticale, and C. Kraub, "Distributed privacy-preserving aggregation of metering data in smart grids," IEEE Journal on Selected Areas in Communications, vol. 31, pp. 1342-1354, Jul. 2013.

[18] Z. Liu, Q. Wu, M. Shahidehpour, C. Li, S. Huang, and W Wei, "Transactive real-time electric vehicle charging management for commercial buildings with PV on-site generation," IEEE Trans. Smart Grid, vol. 10, pp. 4939-4950, Sep. 2019.

[19] Y. Renani, M. Ehsan, and M. Shahidehpour, "Optimal transactive market operations with distribution system operators," IEEE Trans. Smart Grid, vol. 9, pp. 6902-6701, Nov. 2018.

[20] A. Safdarian, M. Fotuhi-Firuzabad, M. Lehtonen, and F. Aminifar, "Optimal electricity procurement in smart grids with autonomous distributed energy resources," IEEE Trans. Smart Grid, vol. 6, pp. 2975-2984, Nov. 2015.

[21] N. Paterakis, O. Erdinc, I. Pappi, A. Bakirtzis, and J. Catalao, "Coordinated operation of a neighborhood of smart households comprising electric vehicles, energy storage and distributed generation," IEEE Trans. Smart Grid, vol. 7, pp. 2736-2747, Nov. 2016.

[22] Z. Tian, J. Ma, Q. Sun, J. Zhao, and W. Wu, "A fully distributed power flow algorithm with exponentially fast convergence," in IEEE Conf. Energy Internet and Energy System Integration, 2018, pp. 1-5.

[23] I. Nejdawi, K. Clements, and P. Davis, "An efficient interior point method for sequential quadratic programming based optimal power flow," IEEE Trans. Power Syst., vol. 15, pp. 1179-1183, Nov. 2000.

[24] J. Morales, and S. Pineda, "On the inefficiency of the merit order in forward electricity markets with uncertain supply," European J. Operational Research, vol. 261, pp. 789-799, Sep. 2017.

[25] S. Hanif, H. Gooi, T. Massier, T. Hamacher, and T. Reindl, "Distributed congestion management of distribution grids under robust flexible buildings operations," IEEE Trans. Power Syst., vol. 32, pp. 4600-4613, Nov. 2017.

[26] D. Kirschen, and G. Strbac, Fundamentals of power system economics, 1st ed. John Wiley \& Sons, 2004.

[27] S. Kazempour, A. Conejo, and C. Ruiz, "Strategic bidding for a large consumer," IEEE Trans. Power Syst., vol. 30, pp. 848-856, Mar. 2015.

[28] J. Wang, H. Zhong, Q. Xia, and C. Kang, "Optimal planning strategy for distributed energy resources considering structural transmission cost allocation," IEEE Trans. Smart Grid, vol. 9, pp. 5236-5248, Sep. 2018.

[29] O. Erdinc, "Economic impacts of small-scale own generating and storage units, and electic vehicles under different demand response strategies for smart households," Appl. Energy, vol. 126, pp. 142-150, May. 2014.

[30] C. Shao, X. Wang, M. Shahidehpour, X. Wang, and B. Wang, "Partial decomposition for distributed electric vehicle charging control considering electric power grid congestion," IEEE Trans. Smart Grid, vol. 8, pp. 75-83, Jan. 2017.

[31] National travel survey, Department for Transport, U.K. [Online]. Available: https://www.gov.uk/government/statistical-data-sets/nts05-trips. 
[32] D. Nguyen, and L. Le, "Optimal bidding strategy for microgrids considering renewable energy and building thermal dynamics," IEEE Trans. Smart Grid, vol. 5, pp. 1608-1620, Jul. 2014.

[33] S. Chen, H. Gooi, and M. Wang "Sizing of energy storage for microgrids," IEEE Trans. Smart Grid, vol. 3, pp. 142-151, Mar. 2012.

[34] H. Heitsch, et al, "Scenario reduction algorithms in stochastic programming," Comp. Opti. and Appl., vol. 24, pp. 187-206, Feb. 2003.

[35] Market data, Nord Pool [Online]. Available: http://www.nordpoolspot.com/Market-data1/\#/nordic/table. 